\title{
Biyodizel Yan Ürünü Olan Gliserolden Üretilen Katalizör ile Yakıt Katkı Maddesi Bütil Levulinat Sentezi
}

\author{
Derya ÜNLÜ* \\ Kocaeli Üniversitesi, Kimya Mühendisliği Bölümü, Kocaeli
}

\begin{abstract}
$\ddot{\mathbf{O} z}$
Biyodizelin yan ürünü olarak gliserol üretiminin fazlalığı gliserolün değerlendirilmesi için araştırmacıları yeni ürün arayışlarına itmiştir. Bu çalışmada biyo-türevli gliserol, tek bir adımda karbonizasyon ve sülfonasyon yoluyla heterojen katı asit katalizör sentezi için bir karbon başlatıcısı olarak kullanılmıştır. Üretilen katalizör, yakıt biyokatkı maddesi bütil levulinat sentezlemek üzere levulinik asit ile bütanolün esterleşme reaksiyonunu katalizlemek için kullanılmıştır. Katalizör karakterizasyonu; FTIR, TGA ve XRD cihazları kullanılarak yapılmıştır. Katalizörün katalitik aktivitesini belirlemek için deneyler farklı reaksiyon sıcaklıklarında, farklı molar besleme oranlarında ve farklı katalizör yükleme oranlarında kesikli reaktörde gerçekleştirilmiştir. En yüksek dönüşüm değeri $70^{\circ} \mathrm{C}$ 'de, molar besleme oranı (alkol/asit) 9:1 kullanılarak ve $\% 7$ katalizör yükleme oranında altı saatin sonunda \%96.25 olarak elde edilmiştir. Katalizör esterleşme reaksiyonunun polar ortamından zarar görmemektedir. Bu nedenle, katalitik aktivitesini kaybetmeden sekiz kez tekrar kullanılmıştır.
\end{abstract}

Anahtar kelimeler: Biyodizel, Bütil Levulinat, Gliserol, Karbon Katalizör, Levulinik Asit.

\section{Synthesis of Fuel Additive Butyl Levulinate by Biodiesel Byproduct Glycerol Derived Catalyst}

\begin{abstract}
Researchers search of new products for the consumption of the excess glycerol which is produced as byproduct of biodiesel. In this study, bio-derived glycerol was used as a carbon precursor for heterogeneous solid acid catalyst synthesis via partial sulphonation and carbonization in a single step. The as-produced catalyst was used to catalyze levulinic acid esterification reaction with butanol to synthesize fuel bioadditive butyl levulinate. Catalyst characterization was carried out by using FTIR, TGA and XRD equipments. Experiments were conducted at different reaction temperatures, different molar feed ratios, and different catalyst loading ratios in a batch reactor for determination of the catalytic activity of the catalyst. The highest conversion value was obtained as $96.25 \%$ for $6 \mathrm{~h}$ while the reaction conditions are reaction temperature of $70^{\circ} \mathrm{C}$, molar feed ratio of (alcohol/acid) 9:1, catalyst concentration of $7 \mathrm{wt} . \%$. The catalyst does not damage in polar reaction medium. For this reason, it was reused eight times without losing catalytic activity.
\end{abstract}

Keywords: Biodiesel, Butyl Levulinate, Glycerol, Carbon Catalyst, Levulinic Acid.

\section{Giriş}

Hızlı nüfus artışı ve artan endüstriyel gelişmeler enerji ihtiyacının giderek artmasına sebep olmaktadır. $\mathrm{Bu}$ artış; petrol rezervlerinin tükenmesi, küresel ısınma ve çevresel sorunlara neden olurken biyokütleden elde edilen yenilenebilir biyoyakıtlara olan ilgiyi de arttırmıştır. Ayrıca petrol rezervlerinin azalması, alternatif enerji kaynaklarının geliştirilmesine yönelik yürütülen çalışmaların artmasını sağlamıştır. Biyokütle alternatif enerji kaynaklarından biri olarak son yıllarda yapılan çalışmalarda oldukça öne çıkmaktadır. Biyokütle temelli yakıtlar, çevreci özellikleri ve yenilenebilir yapılarından dolayı fosil yakıtlara alternatiftirler. $\mathrm{Bu}$ yakıtlar $\mathrm{CO}_{2}$ emisyonunu azaltarak çevre kirliliğini azaltırlar.

*Sorumlu yazar: deryaunluu@gmail.com

Geliş Tarihi: 14.08.2018, Kabul Tarihi: 31.10 .2018 
Bu sebeple yenilenebilir enerji kaynaklarından biyokütle kökenli biyodizel, temiz ve ucuz bir alternatif yakıt olarak oldukça ilgi görmektedir [1].

Biyodizel üretimi, petrol türevli yakıtlara göre sahip olduğu avantajlarından dolayı son birkaç yıldır sürekli artmaktadır. Biyodizel yenilenebilir bir enerji kaynağı olması, biyobozunur olması, toksik olmaması ve sülfürlü ya da aromatik türleri yapısında bulundurmaması gibi özelliklerinden dolayı kısa zamanda uygulanabilir ve gelişen kaynaklardan biri olarak ortaya çıkmıştır [1-3].

Biyodizel üretim prosesinin yan ürünü olan gliserol proses ekonomisini oldukça fazla etkiler. $100 \mathrm{~kg}$ biyodizelden $10 \mathrm{~kg}$ atık gliserol elde edilmektedir. Bu yüzden atık gliserolün yüksek değerli kimyasallara dönüşümü biyodizelin ekonomisi açısından önemlidir. Literatürde bu poliolün değerli ürünlere dönüşümü rapor edilmiştir. Gliserol; eterifikasyon, hidrojenoliz, oksidasyon, transesterifikasyon ve dehidrasyon gibi çeşitli metotlarla farklı kimyasallara dönüştürülebilmektedir [4]. $\mathrm{Bu}$ çalışmada ise tüm bunlardan farklı olarak gliserolden yeşil heterojen katalizör sentezlenerek karakterizasyon testleri yapılmış ve yakıt katkı maddesi bütil levulinatın sentez reaksiyonu olan esterleşme reaksiyonunda katalitik aktivitesi incelenmiştir.<smiles>CCCCOC(=O)CCC(C)=O</smiles>

Şekil 1. Levulinik asit ve bütanolün esterleşme reaksiyonu

Bütil levulinat üretimi, levulinik asit ile bütanolün homojen ya da heterojen katalizörler varlığında esterleşme reaksiyonu ile gerçekleşir. Şekil 1'de levulinik asit ile bütanolün esterleşme reaksiyonu gösterilmiştir. Özellikle homojen katalizörlerle kısa sürede yüksek verim elde edilmesi mümkündür. Ancak homojen katalizörler toksik, korozif, çevreye zararlı ve reaksiyondan geri kazanımı zor olan katalizörlerdir. Bu yüzden bu tür katalizörleri çevreci katalizörlerle değiştirmek önem kazanmaktadır. $\mathrm{Bu}$ homojen katalizörlerin dezavantajlarının üstesinden gelmek için heterojen katalizörler tercih edilmektedir. Heterojen katalizörlerin geri kazanımı ve tekrar kullanılabilirliği mümkündür [5,6]. Literatürde bütil levulinat sentezinde reçineler, zeolitler, heteropoliasitler gibi çeşitli katı asit katalizörleri kullanılmıştır [7-10]. Bu katalizörler su varlığında asit katalizli reaksiyonlarda yeterli performans sağlayamazlar. $\mathrm{Bu}$ nedenle, basit hazırlama yöntemleri kullanılarak, reaksiyon ortamında çözünmeyecek, reaksiyon sonrası yapısında değişim gözlenmeyecek, güçlü aktif bölgelere sahip, yeniden kullanılabilen, ekonomik ve suya dayanıklı katı-asit katalizörlerinin sentezlenmesine ihtiyaç vardır. Bu özelliklere sahip karbon temelli katı asit katalizörleri, substratı konsantre halde 15 saat $250{ }^{\circ} \mathrm{C}^{\prime} \mathrm{de}$ isitmak suretiyle benzen, naftalen, antrasen, perilen ve koronen gibi aromatik hidrokarbonlardan sentezlenmektedir. Ancak bu katalizörlerinde $100{ }^{\circ} \mathrm{C}$ 'nin üzerinde sıv1 faz reaksiyonda çözünme, hızlı katalitik aktivite kaybı gibi bazı dezavantajları vardır. Karbon katalizörlerin diğer bir sınıfi; şeker, nişasta veya selüloz gibi doğal ürünlerin karbonizasyonu ve ardından sülfonasyonu ile elden edilen karbon katalizörlerdir. Bu katalizörlerinde sentezi uzun ve yorucudur. Öncelikle substrat $400{ }^{\circ} \mathrm{C}$ 'ye 1sitılır, sonrasında büyük hacimde konsantre sülfirik asitle 15 saat 150 ${ }^{\circ} \mathrm{C}$ 'de sülfolanır. Bu çalışmada ise, sülfonik gruplar içeren karbon katalizör, ekonomik bir hammadde olan biyozidel yan ürünü olan gliserolden üretilmiştir. Gliserol bazlı karbon katalizörü, karbonizasyon ve gliserolün sülfürik asit ile sülfonasyonu ile 40 dakika içinde tek adımda sentezlenmiştir. Sülfolanmış gliserol temelli karbon katalizör, su ve organik çözücülerde çözünmez ve katalizörün asit bölgeleri esterleşme reaksiyonundan üretilen polar ortamdan zarar görmez [11]. Bu nedenle sentezlenen katalizör bütil levulinat sentezi ve diğer asit katalizörlü reaksiyonlar için umut vaat edici bir katalizördür.

Literatürde gliserol temelli karbon katalizörün kullanıldığı farklı uygulamalar mevcuttur. Okoye ve arkadaşları gliserol temelli karbon katalizörün katalitik aktivitesini gliserol ile asetik asitin esterleşme reaksiyonunda incelemişlerdir. $110{ }^{\circ} \mathrm{C}$ reaksiyon sıcaklığında, gliserolün asetik asite molar oranı 3 ve ağırlıkça $\% 2$ katalizör miktarında 3 saatin sonunda $\% 88$ diasetin ve triasetin seçiciliği ve $\% 99$ gliserol dönüşümü elde etmişlerdir [12]. Devi ve arkadaşları ise biyodizel sentezinde gliserol temelli karbon katalizörü kullanmışlardır. Palmitik asit ve metanolün esterleşme reaksiyonu ile biyodizel üretiminde $65{ }^{\circ} \mathrm{C}$ 'de, ağırlıkça \%10 katalizör varlığında 4 saatin sonunda \% 99 dönüşüm elde etmişlerdir [11]. Bir başka çalışmada ise Varkolu ve arkadaşları, levulinik asit ile etanolün esterleşme reaksiyonunu gliserol temelli karbon katalizör varlığında gerçekleştirmişlerdir. Deneysel çalışmalar sonucunda \%99 etil 
levulinat verimi elde etmişlerdir [13]. Ummadisetti ve arkadaşları gliserol temelli karbon katalizörü kullanarak pentaeritritol diasetallerini üretmişlerdir. Katalizörlerin aktivitesini kaybetmeden ve reaksiyon karışımında çözünmeden 5 kez kullanılabileceğini ifade etmişlerdir [14]. Ribeiro ve arkadaşları katalitik ıslak peroksit oksidasyonunda gliserol temelli karbon katalizörü kullanmışlardır. 2nitrofenolün katalitik bozunmasında \%80 dönüşüm elde etmişlerdir [15]. Gangadhar ve arkadaşları 1oktanolün asetilasyonunu ağırlıkça \% 10 gliserol temelli karbon katalizörün varlığında gerçekleştirmişler ve $\% 90$ verim elde etmişlerdir [16].

$\mathrm{Bu}$ çalışmada gliserolden sentezlenen katalizör öncelikle XRD, FTIR ve TGA kullanılarak karakterize edilmiştir. Ardından katalitik aktivitesi levulinik asit ile bütanolün esterleşme reaksiyonunda test edilmiştir. Reaksiyon sıcaklığının, katalizör miktarının ve molar besleme oranının asit dönüşümüne etkisi incelenmiştir. Katalizörün katalitik dayanımı da tekrar kullanılabilirlik deneyleri ile incelenmiştir.

\section{Materyal ve Metot}

\subsection{Materyaller}

Yakıt katkı maddesi bütil levulinat sentezinde kullanılan reaktanlar levulinik asit ve bütanol ile katalizör hazırlamada kullanılan gliserol Merck firmasından temin edilmiştir. Sülfirik asit ise Sigma Aldrich firmasından satın alınmıştır.

\subsection{Katalizör Hazırlama}

Ağırlıkça \%20 gliserol ve \%80 sülfürik asit içeren çözelti oda sıcaklığından $180{ }^{\circ} \mathrm{C}$ 'ye isıtılarak karıştırılmıştır. Bu 1sıtma esnasında karbonlaşma ve sülfonasyon işlemi gerçekleşmektedir. Çok halkalı aromatik karbon bileşiğinin eldesi ve oluşan köpügün kesilmesi için çözelti yaklaşık 30 dakika $180^{\circ} \mathrm{C}$ 'de tutulmuştur. Sonrasında elde edilen ürün oda sıcaklığına soğutulmuştur. Soğuyan malzeme yıkama suyu nötr pH değerini gösterene kadar sıcak su ile karıştırılarak yıkanmıştır. Kristallenen ürün filtre edilerek gliserol temelli karbon katalizör elde etmek için $120{ }^{\circ} \mathrm{C}$ 'de 2 saat kurutulmuştur [11].

\subsection{Katalizör Karakterizasyonu}

Gliserol temelli karbon katalizörün kristal yapısı X-1şını difraktometresinde (XRD) analiz edilmiştir. Analiz, Miniflex 2 Rigakku Japan X-ışını difraktometresinde $\mathrm{Cu} X$-Işııı tüpü $(\lambda(\mathrm{CuK} \alpha)=0.15418 \mathrm{~nm})$ kullanılarak yapılmıştır. Test parametreleri $45 \mathrm{kV}, 40 \mathrm{~mA}, 0.02$ derecelik açı aralığı ve çekim hızı $2 \% \mathrm{dk}$ olarak alınmıştır. Analizler 6-80 $2 \theta$ (2 Theta) aralığında gerçekleştirilmiştir.

Hazırlanan gliserol temelli karbon katalizörün bağ yapıları Fourier Dönüşümlü Infrared Spektrofotometre (FTIR) cihazı ile analiz edilmiştir. FTIR analizi Kocaeli Üniversitesi Kimya Mühendisliği Bölümü Polimer Laboratuarı'ndaki Perkin Elmer marka cihaz ile yapılmıştır. Analizler $4000-650 \mathrm{~cm}^{-1}$ dalga boyları arasında yapılmıştır.

Katalizörün termal dayanımı ise Kocaeli Üniversitesi Kimya Mühendisliği Bölümü Polimer Laboratuarı'ndaki Mettler Toledo Termogravimetrik Analiz (TGA) cihazı kullanılarak incelenmiştir. Gliserol temelli karbon katalizör örneği oda sıcaklığından $800{ }^{\circ} \mathrm{C}$ 'ye $10^{\circ} \mathrm{C} / \mathrm{dk}$ isınma hızı ile 1 sıtıllmıştır.

\subsection{Bütil Levulinat Sentezi}

Bütil levulinat levulinik asit ile bütanolün esterleşme reaksiyonu ile elde edilmiştir. Reaktanlar ayrı ayrı reaksiyon sıcaklığına 1 sıtılmış ve sonrasında bir araya getirilerek karıştırılmıştır. Karışıma gliserol temelli katalizör ilave edilerek reaksiyon başlatılmıştır. Reaksiyon üç boyunlu cam reaktörde gerçekleştirilmiştir. Reaksiyonda sıcaklık ve karıştırma işlemi için 1sıtıcılı manyetik karıştırıcı kullanılmıştır. Reaksiyon sıcaklığı termokapl ile kontrol edilmiştir. Reaksiyon 500 rpm karıştırma hızında gerçekleştirilmiştir. Reaksiyon sırasında meydana gelebilecek buharlaşma kayıplarını önlemek için reaktöre bir geri soğutucu bağlanmıştır. Reaksiyon hacmi 50 ml'de sabit tutulmuştur. Reaksiyon süresi 6 saat olarak belirlenmiştir. Saat başı numune alınarak asit dönüşüm değerleri $0.1 \mathrm{M} \mathrm{KOH}$ ile titre edilerek hesaplanmıştır. Fenolftalein indikatör olarak kullanılmıştır. Böylece asit-baz titrasyon tekniği 
kullanılarak levulinik asitin dönüşüm değerleri hesaplanmıştır. Dönüşüm hesabında kullanılan formül Eşitlik 1'de verilmiştir.

$$
x(\%)=\frac{\mathrm{n}_{0}-\mathrm{n}_{\mathrm{t}}}{\mathrm{n}_{0}} * 100
$$

$\mathrm{Bu}$ eşitlikte $\mathrm{n}_{0}$ asitin başlangıç anındaki mol miktarı, $\mathrm{n}_{\mathrm{t}}$ ise reaksiyonun herhangi bir anındaki asit mol değeridir. Asitin mol miktarındaki değişim ise serbest asit miktarı ile belirlenmiştir. Serbest asit miktarı, Eşitlik 2 kullanılarak hesaplanmıştır.

$$
S A(\%)=\frac{\mathrm{N}_{\mathrm{KOH}} \mathrm{V}_{\mathrm{KOH}} \mathrm{MA}_{\mathrm{Asit}}}{1000 * \mathrm{~m}_{\text {numune }}}
$$

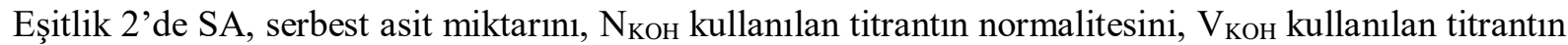
hacmini, $\mathrm{MA}_{\text {asit }}$ levulinik asitin molekül ağırlığını, $\mathrm{m}_{\text {numune }}$ ise titrasyonda kullanılan numune ağırlığını ifade etmektedir [17].

Numuneler aynı zamanda Agilent marka GC-7820A model gaz kromatografisi (GC) cihazında da analiz edilerek, dönüşüm değerlerinin doğruluğu kontrol edilmiştir. Titrasyon ile elde edilen

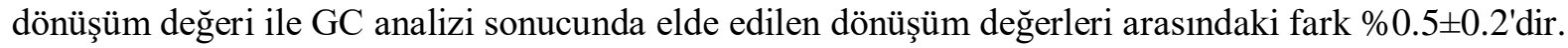
Bütil levulinat sentezi sırasında levulinik asit dönüşümüne reaksiyon sıcaklığının, katalizör miktarının, başlangıç reaktan (alkol/asit) mol oranlarının (M) etkisi incelenmiştir.

\section{Bulgular ve Tartışma}

\subsection{Katalizör Karakterizasyon Sonuçları}

\subsubsection{XRD}

Sentezlenen gliserol temelli karbon katalizörün yapısal analizini belirlemek ve yapıda meydana gelen değişimleri gözleyebilmek için XRD analizleri yapılmış ve bulgular Şekil 2'de verilmiştir.

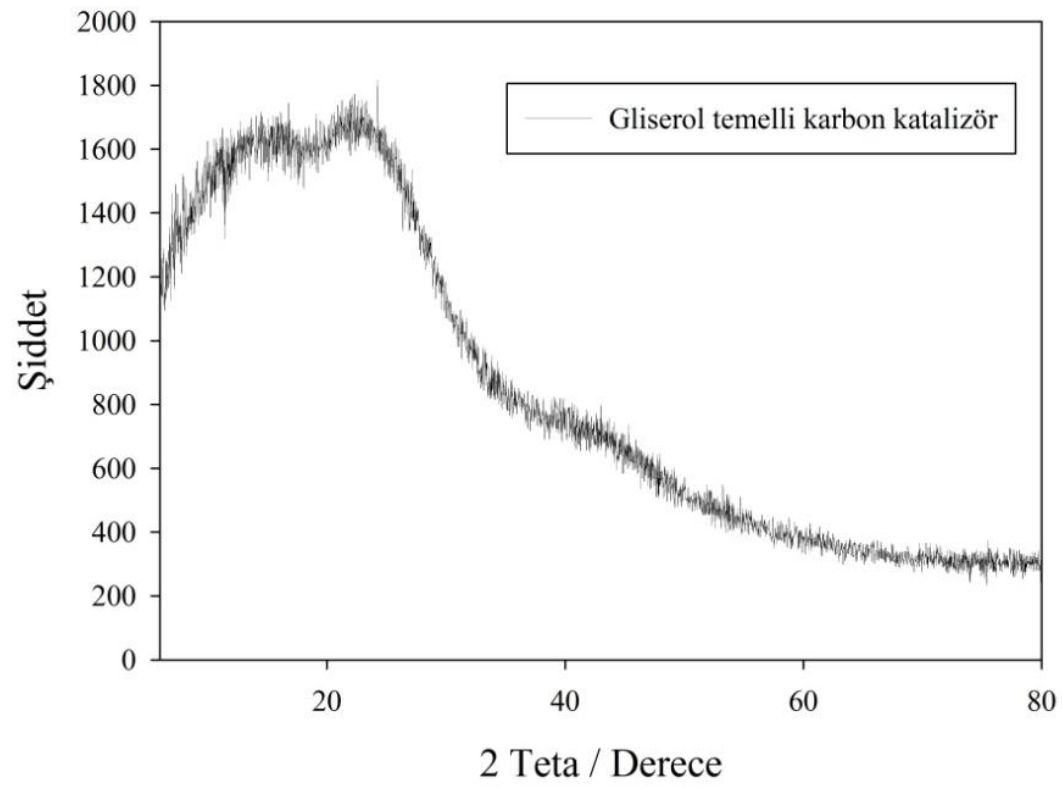

Şekil 2. Gliserol temelli karbon katalizörün XRD analizi

Gliserol temelli karbon katalizörün, 6-20 ve 20-40 arasındaki $2 \theta$ değerlerinde görülen XRD desenleri yapıdaki karbon türlerin amorf yapısını işaret etmektedir. Bu desenler katalizörün amorf 
yapıda olduğunu göstermektedir. XRD analizi ile ayrıca karbon katalizörün, C, H, S, O elementel kompozisyonuna sahip olduğu bulunmuştur [11, 13].

\subsubsection{FTIR}

Gliserol temelli karbon katalizörün bağ yapılarının belirlendiği FTIR spektrumu Şekil 3’te verilmiştir.

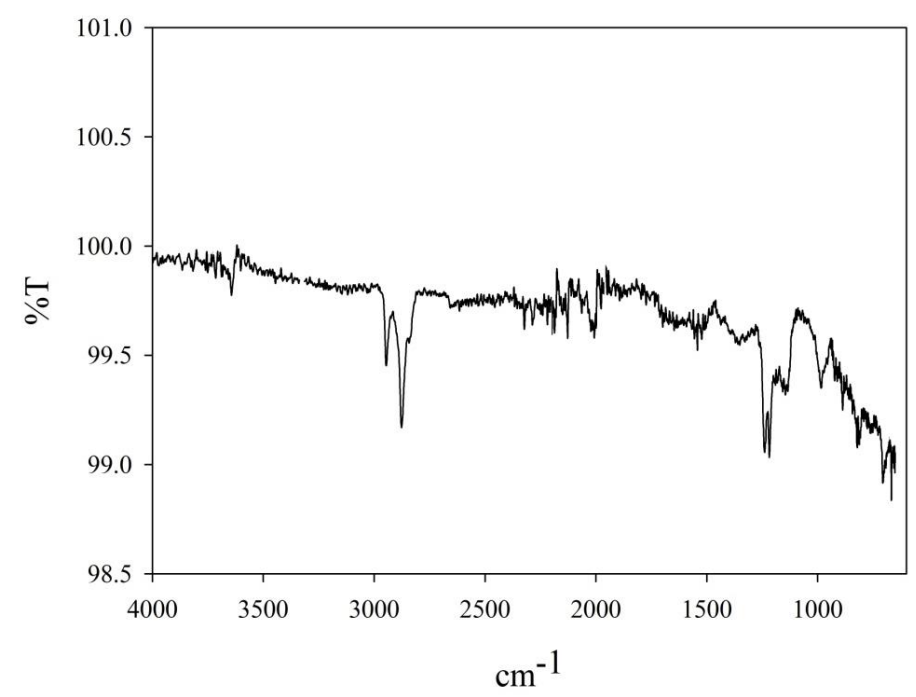

Şekil 3. Gliserol temelli karbon katalizörün FTIR analizi

Gliserol bazlı karbon katalizörün yapısındaki, sülfonik, karbon, karboksil ve fenolik grupların varlığı FTIR analizi ile doğrulanmıştır. FTIR'da 1470 ve $1029 \mathrm{~cm}^{-1}$, deki pikler, gliserol temelli katalizörlerin aktif bölgeleri olan $-\mathrm{SO}_{3} \mathrm{H}$ gruplarını göstermektedir. 3100 ve $2800 \mathrm{~cm}^{-1}$ deki pikler polisiklik aromatik karbonun, karboksilik ve fenolik grupların varlığını işaret etmektedir. $1013-990 \mathrm{~cm}^{-}$ ${ }^{1}$,deki pikler ise (-C=C-) aromatik karbonu ifade etmektedir $[11,12]$.

\subsubsection{TGA}

Şekil 4'te karbon katalizörün TGA eğrisi gösterilmiştir.

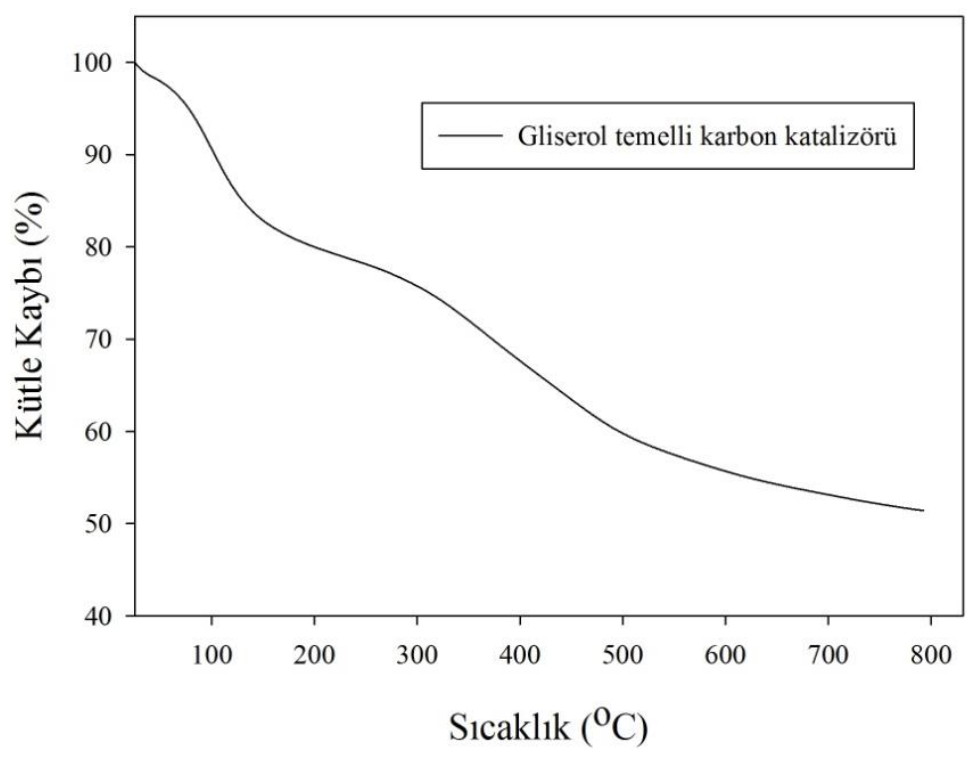

Şekil 4. Gliserol temelli karbon katalizörün TGA eğrisi 
Karbon katalizörün termal bozunma davranışı, ilk olarak $100-120{ }^{\circ} \mathrm{C}$ aralığında yapıda fiziksel adsorbe olan nem içeriğinin desorpsiyonuna bağlı olarak gerçekleşmiştir. Sonrasında $400{ }^{\circ} \mathrm{C}$ 'ye kadar görülen kütle kaybı ise sülfolanmış katalizörün yapısında buluna $\mathrm{SO}_{3} \mathrm{H}$ gruplarının bozunması ile ilgilidir. $400^{\circ} \mathrm{C}-500^{\circ} \mathrm{C}$ aralığında görülen kütle kaybı ise katalizörün yapısındaki Bronsted asit bölgelerinin bozunmasından ileri gelmektedir [18]. $500^{\circ} \mathrm{C}$ 'nin üzerinde gerçekleşen kütle kaybı ise, yoğun isı nedeni ile katalizörün yapısında bulunan karbonun yanması ile açıklanabilir [19].

\subsection{Bütil Levulinat Sentez Reaksiyonu}

\subsubsection{Reaksiyon süresinin belirlenmesi}

Reaksiyon süresinin belirlenmesi için levulinik asit ile bütanolün esterleşme reaksiyonu; $70^{\circ} \mathrm{C}$ 'de, $\mathrm{M}=3$ molar besleme oranında, ağırlıkça levulinik asit ağırlığının \%7'si kadar katalizör kullanılarak kesikli reaktörde gerçekleştirilmiştir. Reaksiyon dönüşümü 12 saat boyunca izlenmiş ve saat başı numune alınarak analiz edilmiştir.

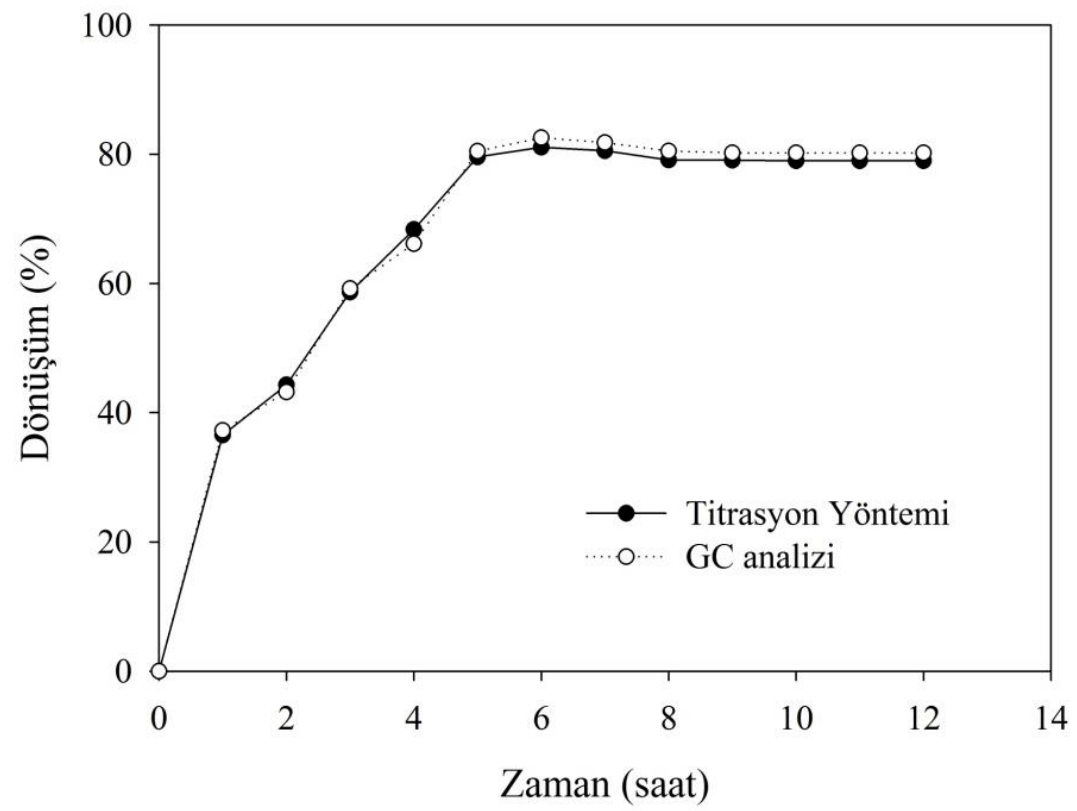

Şekil 5. Reaksiyon süresinin levulinik asit dönüşümüne etkisi $\left(\mathrm{T}=70{ }^{\circ} \mathrm{C}\right.$, ağıllıkça $\% 7$ katalizör, $\left.\mathrm{M}=3\right)$

Esterleşme reaksiyonları denge limitli, tersinir reaksiyonlardır. Bu yüzden yüksek dönüşüm değeri elde etmek oldukça güçtür ve uzun zaman alır. Şekil 5'te kesikli reaktörde gerçekleştirilen deneylerde levulinik asit dönüşümünün zamanla değişimi gösterilmiştir. Levulinik asit dönüşümü altınc1 saate kadar artış göstermiştir. Altıncı saatin sonunda ise çok az bir düşüş gözlenmiş ve sonrasında sabit kalmıştır. Bu durum reaksiyonun altı saatte dengeye ulaştı̆̆ını göstermektedir. Bu nedenle reaksiyon süresi altı saat olarak belirlenmiştir. Ayrıca Şekil 5'te titrasyon yöntemi ve GC analizi sonucunda elde edilen levulinik asit dönüşüm değerleri karşılaştırılmıştır. Her iki analiz yöntemi sonucunda elde edilen dönüşüm değerlerinin birbirine oldukça yakın olduğu görülmüştür. Titrasyon ile elde edilen dönüşüm değeri ile GC analizi sonucunda elde edilen dönüşüm değerleri arasındaki fark $\% 0.5 \pm 0.2$ 'dir. Bu da her iki analiz sonucunda elde edilen dönüşüm değerlerinin doğruluğunu ortaya koymaktadır.

\subsubsection{Karıştırma hızının asit dönüşümüne etkisi}

Karıştırma hızının bütil levulinat sentezinde levulinik asit dönüşümüne etkisini belirlemek için 300, 400, 500 ve $600 \mathrm{rpm}$ karıştırma hızlarında $70^{\circ} \mathrm{C}$ 'de, ağırlıkça $\% 7$ katalizör kullanılarak, M=3:1 molar besleme oranında deneyler gerçekleştirilmiştir. Elde edilen verilerden asit dönüşümü hesaplanmış ve Şekil 6'da gösterilmiştir. 


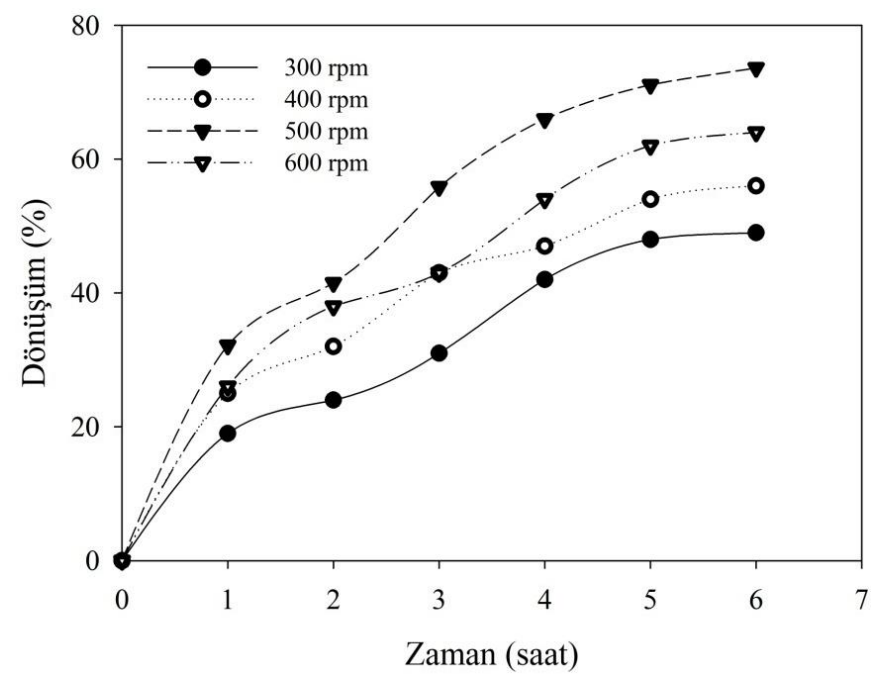

Şekil 6. Karıştırma hızının asit dönüşümüne etkisi ( $M=3: 1, \% 7$ katalizör)

Karıştırma hızı arttıkça başlangıçta asit dönüşümünün arttığı, sonrasında ise azaldığ1 görülmüştür. Karıştırma hızının artması katalizör yüzeyinde oluşan kütle transfer direncini ortadan kaldırmaktadır [20]. Gliserolden üretilen karbon katalizör, heterojen katalizördür. Heterojen reaksiyonlarda reaksiyon mekanizması kütle transferi ya da yüzey reaksiyonu ile kontrol edilmektedir. Karıştırma hızı arttıkça asit dönüşümünün artması reaksiyonu kontrol eden mekanizmanın kütle transferi olduğunu göstermektedir [21]. Karıştırma hızı 300 rpm'den 500 rpm'e arttıkça, asit dönüşümü artmış ancak hız 600 rpm'e ulaştığında dönüşüm değeri azalmıştır. 500 rpm'in altındaki karıştırma hızlarında asit dönüşümünün düşük olması katalizör yüzeyinde oluşan kütle transfer direncinin aşılamamasından kaynaklanmaktadır. Bu durumda reaksiyon karışımı ile katalizör arasındaki etkileşim düşük olmakta, bu nedenle yüksek dönüşüm elde edilememektedir. 500 rpm'in üzerindeki karıştırma hızında ise, yüksek karıştırma hızından dolayı heterojen katalizör, reaktörün cidarına doğru dağılmakta, cidara yapışmakta ve reaksiyon karışımında homojen dağılmamaktadır. Bu nedenle katalizör ile reaksiyon karışımının doğrudan teması mümkün olmamaktadır. Karıştırma hızı 300 rpm'den 500 rpm'e arttırıldığında asit dönüşümü \%49'dan \%73'e artarken, 600 rpm karıştırma hızında asit dönüşümü \%64'e düşmüştür. Bu nedenle en yüksek dönüşümün elde edildiği 500 rpm karıştırma hızı optimum değer olarak belirlenmiştir ve tüm reaksiyonlar bu karıştırma hızı sabit tutularak gerçekleştirilmiştir.

\subsubsection{Reaksiyon sıcaklığının asit dönüşümüne etkisi}

Sıcaklık, reaksiyon dönüşümünü etkileyen önemli bir faktördür [22]. Reaksiyon sıcaklığının levulinik asit dönüşümüne etkisi Şekil 7'de görülmektedir.

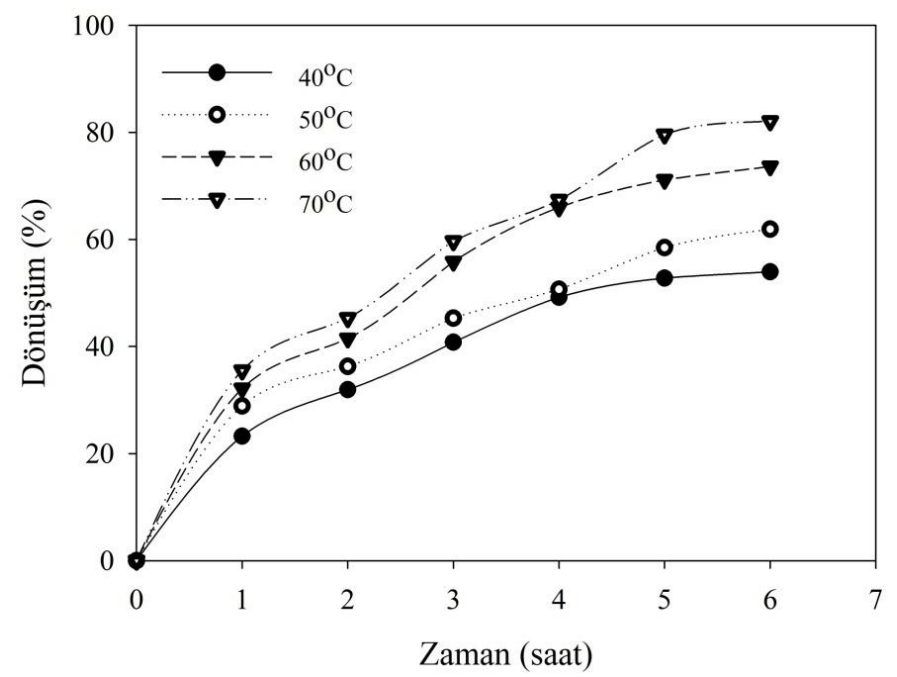

Şekil 7. Reaksiyon sıcaklığının asit dönüşümüne etkisi ( $\mathrm{M}=3: 1, \% 7$ katalizör) 
Yüksek sıcaklık, yüksek reaksiyon dönüşümü ile sonuçlanır. Sıcaklık artışı ile reaksiyon hızı ve ester üretimi artar [23]. Dönüşüm değerinin sıcaklık ile artması, reaksiyonun endotermik olduğunun ve denge sabitinin sıcaklık ile arttığının göstergesidir [24]. Ayrıca levulinik asit ile bütanolün esterleşme reaksiyonu bir denge reaksiyonudur. Hem endotermik olmas 1 hem de denge reaksiyonu olması sebebiyle sıcaklık artışı ürünler yönünde reaksiyonu hızlandırır ve dönüşüm $\operatorname{artar}[25,26]$. Esterleşme reaksiyonları için reaksiyon hız sabiti sıcaklığın fonksiyonudur ve sıcaklık ile artar. Bu nedenle de ester üretim hızı yüksek sıcaklıkta düşük sıcaklığa göre daha yüksektir. Ayrıca operasyon sıcaklığındaki artış, moleküler çarpışmayı arttırır, kimyasal bağları kırar ve reaktanların karışabilirliğini kolaylaştırır. Böylece reaksiyon hızı ve levulinik asit dönüşümü artar [25]. Yüksek sıcaklıkta ürünlerin üretim hızı yüksektir [27].

Reaksiyon sıcaklığının dönüşüme etkisi $40,50,60$ ve $70{ }^{\circ} \mathrm{C}$ 'de molar besleme oranı alkol/asit 3 iken, ağırlıkça $\% 7$ katalizör yüklü reaktörde incelenmiştir. Sıcaklık $40{ }^{\circ} \mathrm{C}$ 'den $70{ }^{\circ} \mathrm{C}$ 'ye çıktığında dönüşüm değeri \%53.95'ten \%82.07'e artmıştır.

\subsubsection{Katalizör miktarının asit dönüşümüne etkisi}

Katalizör miktarının reaksiyon dönüşümüne etkisini incelemek için bütil levulinat sentez reaksiyonu ağırlıç̧a $\% 1, \% 3, \% 5$ ve $\% 7$ oranlarında katalizör ilavesi ile $70^{\circ} \mathrm{C}$ 'de, molar besleme oranı 3 olarak kullanılarak $(\mathrm{M}=3)$ gerçekleştirilmiştir. Elde edilen dönüşüm değerlerinin zamanla ve sıcaklıkla değişimi Şekil 8'de gösterilmiştir.

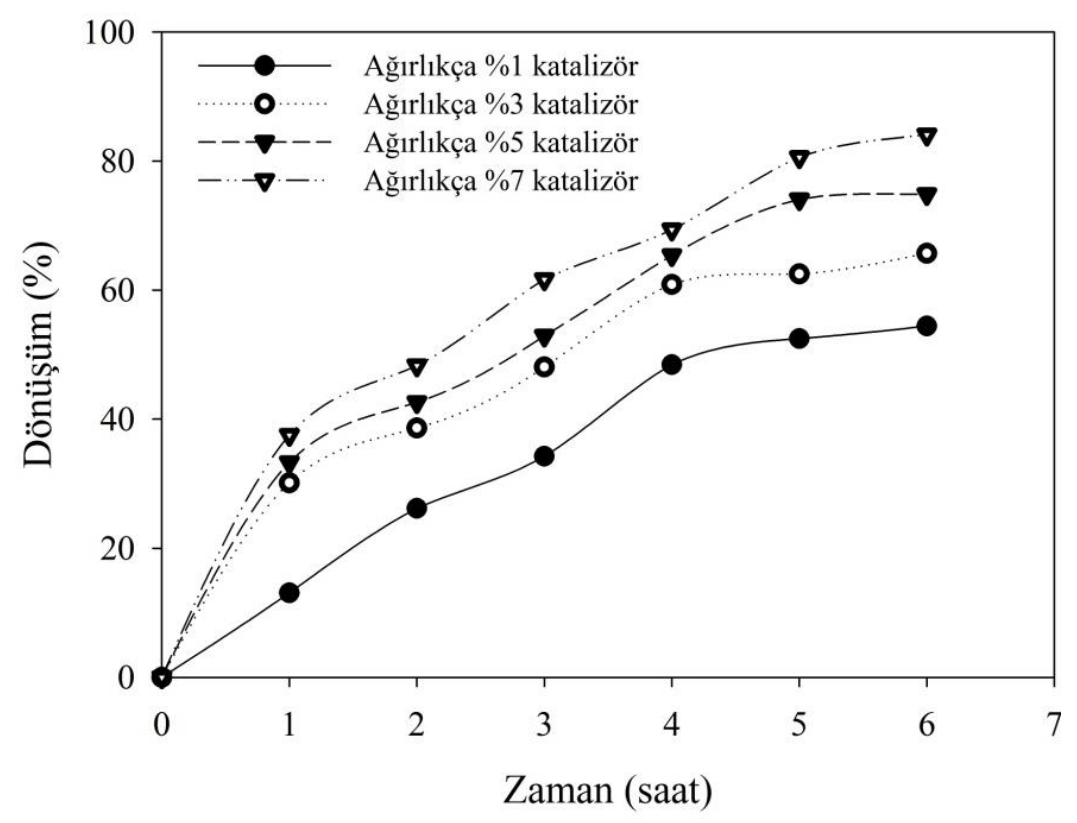

Şekil 8. Katalizör miktarının asit dönüşümüne etkisi $\left(\mathrm{M}=3: 1,70^{\circ} \mathrm{C}\right)$

Şekil 8'de görüldüğü gibi, levulinik asit dönüşümü katalizör miktarı arttıkça artmıştır. Katalizör miktarı, reaksiyon karışımındaki asidin ağırlığının yüzdesi olarak hesaplanmıştır. Katalizör miktarındaki artış reaksiyonu hızlandırır. Çünkü reaksiyon hızı katalizör miktarı ile doğru orantılıdır [28]. Katalizör miktarının artması ile asidik bölgelerin sayısı ve katalizörün aktif yüzey alanı artar. Böylece reaktanlar katalizörün aktif bölgelerine daha kolay ulaşabilir ve dönüşüm artar [29-30]. Ayrıca katalizörün aktif bölgesindeki artış, reaksiyonun aktivasyon enerjisini düşürür ve reaksiyon hızını arttırır [31]. Artan reaksiyon hızı reaksiyonun dengeye ulaşma süresini kısaltır. Maksimum katalizör miktarı ağırlıkça \%7 olarak çalışılmıştır. Çünkü optimum miktarın üzerindeki katalizör yüklemelerinin levulinik asitin dönüşümünü azalttığı görülmüştür. Yüksek katalizör yükleme oranlarında reaksiyon karışımı daha viskoz olmakta ve kütle transfer sınırlaması oluşmakta bu da katalitik aktiviteyi sınırlandırmaktadır [32].

Katalizör miktarı \%1'den \%7'ye arttığında levulinik asit dönüşüm değeri \%54.43'ten \%84.07'ye artmıştır. 


\subsubsection{Molar besleme oranının asit dönüşümüne etkisi}

Tersinir reaksiyonlarda reaktanlardan birinin fazla miktarda kullanılması dönüşümü arttırmanın bir yoludur. Molar besleme oranının reaksiyon dönüşümüne etkisi $M=1: 1, M=3: 1, M=6: 1$ ve $M=9: 1$ molar oranlarında, $\% 7$ katalizör yükleme oranında, $70^{\circ} \mathrm{C}^{\prime}$ de incelenmiştir. Asit dönüşümün molar besleme oranı ile değişimi Şekil 9'da verilmiştir.

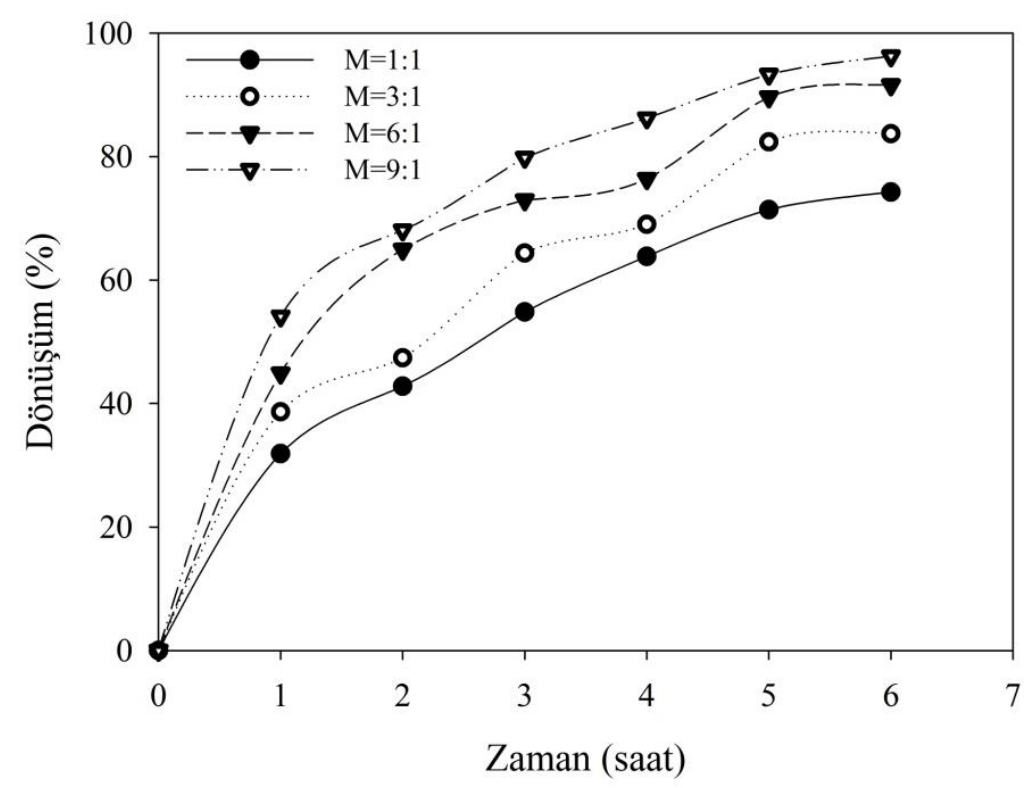

Şekil 9. Molar besleme oranının asit dönüşümüne etkisi $\left(70^{\circ} \mathrm{C}, \% 7\right.$ katalizör $)$

Başlangıç reaktan mol oranı arttıkça levulinik asit dönüşümünün arttığı görülmüştür. Yüksek başlangıç reaktan mol oranları yüksek dönüşüm ile sonuçlanmıştır. Tersinir reaksiyonlarda dönüşümü arttırmanın bir yolu daha öncede bahsedildiği gibi reaktanlardan birinin fazla miktarda kullanılmasıdır. Fazla miktarda alkol kullanımı geri reaksiyon hızını minimize ederek, reaksiyonun ileri yönde devam etmesini sağlar. Le Chatelier prensibine göre reaktanlardan birinin fazla miktarda kullanması dengeyi ürünler yönüne kaydırmış ve bu durum dönüşümün artmasına neden olmuştur. Ayrıca reaktanlardan birinin fazla miktarda kullanılması diğer reaktanla temas olasılığını arttırdığından dolayı asit dönüşümünü de arttırmıştır [33].

Artan molar oran ile yüksek dönüşüm eldesi mümkündür, fakat sınırlayıcı reaktan hiçbir zaman tamamen tükenmez. Bu durumda ürünün saf olarak elde edilmesi ilave ayırma adımı gerektirir ve proses maliyetinin artması ile sonuçlanır [31,33]. Bu yüzden minimum molar besleme oranı ile yüksek dönüşüm elde etmek daha önemlidir. Ayrıca yüksek molar oran, katalizörün seyrelmesi ile sonuçlanır.

Deneysel çalışmalar sonucunda 6 saatin sonunda $M=1: 1, M=3: 1, M=6: 1$ ve $M=9: 1$ 'de sirasılyla $\% 74.25, \% 83.68, \% 91.58$ ve \%96.25 levulinik asit dönüşümü elde edilmiştir.

\subsubsection{Katalizörün tekrar kullanılabilirliği}

Yeniden kullanılabilirlik, heterojen katalizörde çok önemli ve avantajlı bir özelliktir. Katalizörün tekrar kullanımını ve katalitik aktivitesini değerlendirmek için esterleşme reaksiyonu aynı koşullar altında gerçekleştirilmiştir.

Levulinik asitin esterleşme reaksiyonu literatürde çoğunlukla homojen katalizörlerin kullanımı ile gerçekleştirilmiştir. Bu katalizörlerin korozyon, geri kazanım zorluğu gibi bazı dezavantajları vardır. $\mathrm{Bu}$ çalışmada kullanılan heterojen gliserol temelli karbon katalizör, homojen katalizörlere yeşil alternatif olarak tercih edilmiştir. Katalizörün geri kazanımı, prosesin yeşil olarak adlandırılması için önemli bir faktördür. Bu yüzden katalitik dayanım ve tekrar kullanım katalizörler için önemli bir özelliktir [2, 35-36]. 


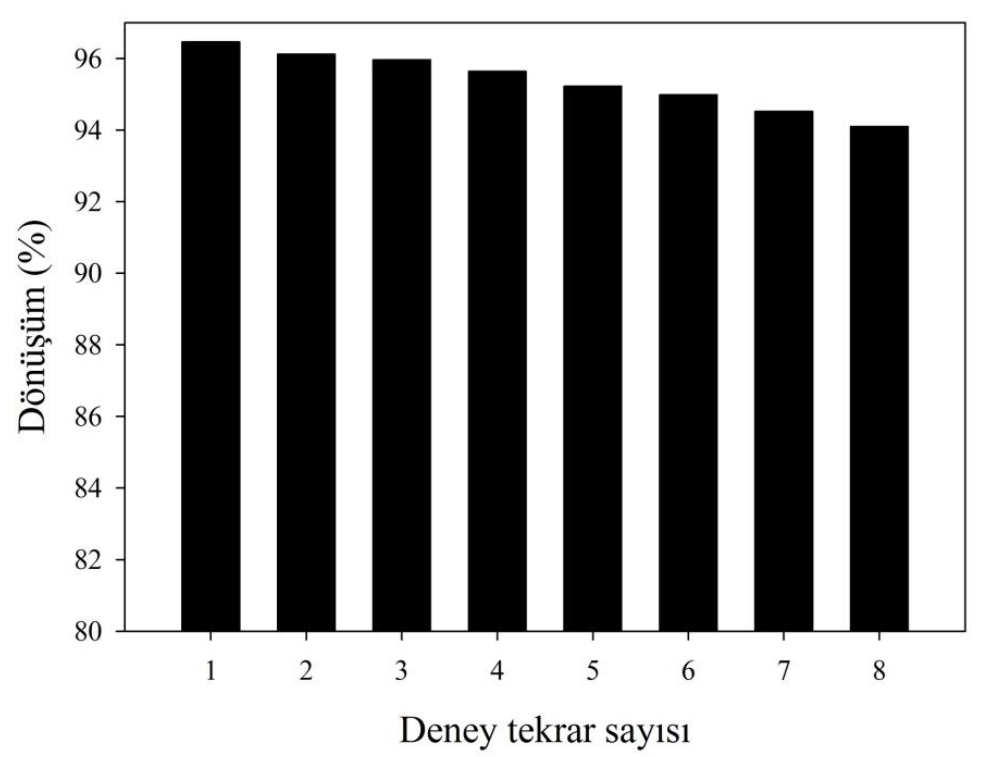

Şekil 10. Katalizörün tekrar kullanılabilirliği $\left(70^{\circ} \mathrm{C}, \mathrm{M}=9: 1, \% 7\right.$ katalizör $)$

Tekrar deneyleri sonucunda elde edilen levulinik asit dönüşümü değerleri Şekil 10'da gösterilmiştir. Gliserol temelli karbon katalizörün tekrar kullanılabilirliği bütanol ile levulinik asitin esterleşme reaksiyonunda ağırlıkça $\% 7$ katalizör miktarında, $70^{\circ} \mathrm{C}$ de, $\mathrm{M}=9: 1$ molar besleme oranında gerçekleştirilmiştir. Katalizör, reaksiyon sonucu reaksiyon ortamından geri alınıp; aynı koşullar altında $8 \mathrm{kez}$ tekrar kullanılmıştır. Her kullanımdan sonra etanol ile yıkanmış, $100^{\circ} \mathrm{C}^{\prime}$ de etüvde bir gece kurutulmuştur. İlk kullanımdan 8. kullanıma kadar benzer dönüşüm değerleri elde edilmiştir, tekrar kullanılan katalizör aynı katalitik aktiviteyi göstermiştir. İlk kullanım sonrasında \%96.46 dönüşüm elde edilirken, sekizinci kullanım sonunda \%94.10 dönüşüm değeri elde edilmiştir. Elde edilen bu sonuçlar katalizörün katalitik aktivitesinde önemli bir kayıp olmadığını göstermiştir. Bu nedenle kullanılan katalizörün, aktif ve tekrar kullanılabilir olduğu sonucuna varılmıştır.

\subsubsection{Elde edilen sonuçların literatür ile karşılaştırılması}

Levulinik asit ile bütanolün esterleşme reaksiyonu sonucu elde edilen dönüşüm değerleri literatürdeki sonuçlarla karşılaştırılmıştır. Bütil levulinat sentezi için literatürde gliserol temelli karbon katalizörün kullanıldığı çalışmaya rastlanmamıştır. Bu sebeple Tablo 1'de verilen dönüşüm değerleri farklı katalizörler kullanılarak elde edilen dönüşüm değerleridir.

Tablo 1. Dönüşüm değerlerinin literatür ile karşılaştırılması

\begin{tabular}{|c|c|c|c|}
\hline Reaksiyon koşulları & Katalizör & $\begin{array}{c}\text { Dönüşüum } \\
(\%)\end{array}$ & Kaynak \\
\hline $\begin{array}{c}\mathrm{T}=100^{\circ} \mathrm{C}, \mathrm{M}=3: 1, \text { ağ. } \% 10 \\
\text { katalizör, } \mathrm{t}=4 \mathrm{sa}\end{array}$ & $\begin{array}{l}\text { Glikoz temelli amorf } \\
\text { karbon }\end{array}$ & 72 & [7] \\
\hline $\begin{array}{c}\mathrm{T}=117,7^{\circ} \mathrm{C}, \mathrm{M}=20: 1, \text { ağ. } \% 30 \\
\text { katalizör, } \mathrm{t}=5 \mathrm{sa}\end{array}$ & Amberlist-15 & 55 & {$[8]$} \\
\hline $\begin{array}{c}\mathrm{T}=120^{\circ} \mathrm{C}, \mathrm{M}=4: 1 ; \mathrm{ağ} . \% 10 \\
\text { katalizör, } \mathrm{t}=4 \mathrm{sa}\end{array}$ & $\begin{array}{c}\text { Montmorillonit K10 } \\
\text { destekli } \\
\text { dodekatungstofosforikasit }\end{array}$ & 87 & [9] \\
\hline $\begin{array}{c}\mathrm{T}=120^{\circ} \mathrm{C}, \mathrm{M}=6: 1, \text { ağ. } \% 10 \\
\text { katalizör, } \mathrm{t}=4 \mathrm{sa}\end{array}$ & H-BEA zeolit & 76.9 & {$[10]$} \\
\hline $\begin{array}{c}\mathrm{T}=70^{\circ} \mathrm{C}, \mathrm{M}=6: 1, \text { ağ. } \% 7 \\
\text { katalizör, } \mathrm{t}=6 \mathrm{sa}\end{array}$ & $\begin{array}{c}\text { Gliserol temelli karbon } \\
\text { katalizör }\end{array}$ & 91.58 & Bu çalışma \\
\hline
\end{tabular}

Tablo 1'de verilen sonuçlara bakıldığında, gliserol temelli karbon katalizör ile bütil levulinat sentezinde daha düşük sıcaklıkta ve daha az katalizör miktarı ile yüksek dönüşüm elde edilmiştir. Elde edilen sonuçlar, gliserol temelli karbon katalizörün 1lımlı koşullar altında gerçekleştirilen bütil levulinat sentez reaksiyonunda katalitik aktivitedeki başarısını ortaya koymuştur. 


\section{Sonuç ve Öneriler}

Biyodizel yan ürünü olan gliserol kullanılarak tek adımda karbonizasyon ve sülfonasyon tekniği ile etkili, ekonomik ve yeniden kullanılabilir bir katı asit katalizörü üretilmiştir. Elde edilen gliserol temelli karbon katalizörün önemli ölçüde yüksek katalitik aktiviteye ve kimyasal dayanıma sahip olduğu sonucuna varılmıştır. Levulinik asit ile bütanol esterleşme reaksiyonu ile bütil levulinat sentezinde gliserol temelli sülfolanmış karbon katalizör oldukça başarılı katalitik aktivite göstermiştir. Katı asit katalizörü termal olarak stabil bulunmuştur. Katalizör reaksiyonda heterojen davranış göstermiştir. Yapısında bulunan sülfonik fonksiyonel gruplar reaksiyonun polar ortamından etkilenmemiş, dolayısıyla katalizör deaktive olmaksızın sekiz kez tekrar kullanılabilmiştir. Elde edilen tüm bu sonuçlardan, çevre dostu gliserol temelli karbon katalizörün esterleşme reaksiyonuna ek olarak farklı asit katalizörlü reaksiyonlar için önemli bir alternatif olduğu sonucuna varılmıştır. Farklı asidik katalizörlü uygulamalar için sıvı asit katalizörlerin yerini alabilecek bir potansiyele sahip olduğu görülmüştür.

\section{Teşekkür}

Katalizör Karakterizasyonunda FTIR ve TGA analizlerini yapmam için cihaz kullanımında yardımlarını ve desteklerini esirgemeyen Kocaeli Üniversitesi Polimer Laboratuvarına teşekkür ederim. Ayrıca Kocaeli Üniversitesi BAP birimine mali desteği için teşekkür ederim (Proje No: 2018/062HD).

\section{Kaynaklar}

[1] Gonçalves V.L.C., Pinto B.P., Silva J.C., Mota C.J.A. 2008. Acetylation of glycerol catalyzed by different solid acids, Catalysis Today, 133-135:73-677.

[2] Rodrígue I.D., Adriany C., Gaigneaux E.M. 2011. Glycerol acetylation on sulphated zirconia in mild conditions, Catalysis Today, 167 (1): 56-63.

[3] Zhu S., Zhu Y., Gao X., Mo T., Zhu Y., Lia Y. 2013. Production of bioadditives from glycerol esterification over zirconia supported heteropolyacids, Bioresource Technology, 130: 45-51.

[4] Khayoon M.S., Hameed B.H. 2012. Synthesis of hybrid SBA-15 functionalized with molybdophosphoric acid as efficient catalyst for glycerol esterification to fuel additives, Applied Catalysis A: General, 433-434: 152-161.

[5] Kuwahara Y., Fujitani T., Yamashita H. 2014. Esterification of levulinic acid with ethanol over sulfated mesoporous zirconosilicates: Influences of the preparation conditions on the structural properties and catalytic performances, Catalysis Today, 237: 18-28.

[6] Fernandes D.R., Rocha A.S., Mai E.F., Mota J.A., Silva V. 2012. Levulinic acid esterification with ethanol to ethyl levulinate production over solid acid catalysts, Applied Catalysis A: General, 425426: 199-204.

[7] Yang J., Li G., Zhang L., Zhang S. 2018. Efficient Production of N-Butyl Levulinate Fuel Additive from Levulinic Acid Using Amorphous Carbon Enriched with Oxygenated Groups, Catalysts, 8 (1): 14 .

[8] Ramli, N.A.S., Zaharudin N.H., Amin N.A.S. 2017. Esterification of Renewable Levulinic Acid To Levulinate Esters Using Amberlyst-15 As A Solid Acid Catalyst, Jurnal Teknologi (Sciences \& Engineering), 79 (1): 137-142.

[9] Dharne S., Bokade V.V. 2011. Esterification of levulinic acid to n-butyl levulinate over heteropolyacid supported on acid-treated clay, Journal of Natural Gas Chemistry, 20: 18-24.

[10] Maheria K.C., Kozinski J., Dalai A. 2013. Esterification of Levulinic Acid to n-Butyl Levulinate Over Various Acidic Zeolites, Catalysis Letters, 143: 1220-1225.

[11] Devi B.LA.P, Gangadhar K.N., Prasad P.S.S, Jagannadh B., Prasad R.B.N. 2009. A Glycerol-based Carbon Catalyst for the Preparation of Biodiesel, ChemSusChem, 2: 617-620.

[12] Okoye P.U., Abdullah A.Z., Hameed B.H. 2017. Synthesis of oxygenated fuel additives via glycerol esterification with acetic acid over bio-derived carbon catalyst, Fuel, 209: 538-544.

[13] Varkolu M., Moodley V., Potwana F.S.W., Jonnalagadda S.B., Zyl W.E. 2017. Esterification of levulinic acid with ethanol over bio-glycerol derived carbon-sulfonic-acid, Reaction Kinetics Mechanisms and Catalysis, 120 (1): 69-80. 
[14] Ummadisetti C., Rachapudi B.N.P., Bethala L.A.P.D. 2014. Glycerol-based SO3H-Carbon Catalyst: A green recyclable catalyst for the chemoselective synthesis of pentaerythritol diacetals, European Journal of Chemistry, 5 (3): 536-540.

[15] Ribeiro R.S., Silva A.M.T., Pinho M.T., Figueiredo J.L., Faria J.L., Gomes H.T. 2014. Development of glycerol-based metal-free carbon materials for environmental catalytic applications, Catalysis Today, 240: 61-66.

[16] Gangadhar K.N., Vijay M., Prasad R.B.N., Devi B.L.A.P. 2013. Glycerol-Based Carbon-SO3H Catalyzed Benign Synthetic Protocol for the Acetylation of Alcohols, Phenols and Amines under Solvent-Free Conditions, Green and Sustainable Chemistry, 3: 122-128.

[17] Ilgen O. 2014. Investigation of reaction parameters, kinetics and mechanism of oleic acid esterification with methanol by using Amberlyst 46 as a catalyst, Fuel Processing Technology, 124: 134-139.

[18] Jamil F., Al-Muhtaseb A.H., Naushad M., Baawain M., Al-Mamun A., Saxena S.K., Viswanadham N. 2017. Evaluation of synthesized green carbon catalyst from waste date pits for tertiary butylation of phenol, Arabian Journal of Chemistry, inpress, DOI: 10.1016/j.arabjc.2017.04.009.

[19] Leal G.F., Ramos L.A., Barrett D.H., Curvelo A.A.S., Rodella C.B. 2015. A thermogravimetric analysis (TGA) method to determine the catalytic conversion of cellulose from carbon-supported hydrogenolysis process, Thermochimica Acta, 616: 9-13.

[20] Mehmet B. 2001. Yağların katalitik hidrojenasyonunda işlem parametrelerinin selektivite ve izomer yap1 oluşumu üzerindeki etkileri. Ege Üniversitesi, Fen Bilimleri Enstitüsü, Doktora tezi, $127 \mathrm{~s}$, İzmir.

[21] Mehmet Y. 2010. Biyodizel Prosesi Yan Ürünü Gliserinin Katalitik Hidrojenasyonu. Eskişehir Osmangazi Üniversitesi, Fen Bilimleri Enstitüsü, Yüksek Lisans tezi, 64s, Eskişehir.

[22] Khayoon M.S., Hameed B.H. 2011. Acetylation of glycerol to biofuel additives over sulfated activated carbon catalyst, Bioresource Technology, 102 (19): 9229-9235.

[23] Zhou L., Al-Zaini E., Adesina A.A. 2013. Catalytic characteristics and parameters optimization of the glycerol acetylation over solid acid catalysts, Fuel, 103: 617-625.

[24] Zhang W., Qing W., Ren Z., Li W., Chen J. 2014. Lipase immobilized catalytically active membrane for synthesis of lauryl stearate in a pervaporation membrane reactor, Bioresource Technology, 172: 16-21.

[25] Karakus S. 2014. Pervaporasyon Esterleşme Hibrit Prosesi ile İzobutil Akrilat Sentezi. Ege Üniversitesi, Fen Bilimleri Enstitüsü, Yüksek Lisans Tezi, 163s, İzmir.

[26] Sert E., Atalay F.S. 2014. n-Butyl acrylate production by esterification of acrylic acid with nbutanol combined with pervaporation, Chemical Engineering and Processing: Process Intensification, 81: 41-47.

[27] Chen Y., Zhang X., Dong M., Wu Y., Zheng G., Huang J., Zheng, X. 2016. MCM-41 immobilized 12-silicotungstic acid mesoporous materials: Structural and catalytic properties for esterification of levulinic acid and oleic acid, Journal of the Taiwan Institute of Chemical Engineers, 61: 147-155.

[28] Jyoti G., Keshav A., Anandkumar J. 2017. Esterification of acrylic acid with ethanol using pervaporation membrane reactor, Korean Journal of Chemical Engineering, 34 (6): 1661-1668.

[29] Parida K.M., Mallick S. 2007. Silicotungstic acid supported zirconia : An effective catalyst for esterification reaction, Journal of Molecular Catalysis A: Chemical, 275: 77-83.

[30] Balaraju M., Nikhitha P., Jagadeeswaraiah K., Srilatha K., Prasad P.S.S., Lingaiah N. 2010. Acetylation of glycerol to synthesize bioadditives over niobic acid supported tungstophosphoric acid catalysts, Fuel Processing Technology, 91 (2): 249-253.

[31] Jyoti G., Keshav A., Anandkumar J. 2015. Review on Pervaporation :Theory, Membrane Performance, and Application to Intensification of Esterification Reaction, Journal of Engineering, 2015: 1-24.

[32] Ramli N.A.S., Sivasubramaniam D., Amin N.A.S. 2017. Esterification of Levulinic Acid Using $\mathrm{ZrO}_{2}$-Supported Phosphotungstic Acid Catalyst for Ethyl Levulinate Production, BioEnergy Research, 10 (4): 1105-1116.

[33] Delgado P., Sanz M.T., Beltrán S., Alberto L. 2010. Ethyl lactate production via esterification of lactic acid with ethanol combined with pervaporation, Chemical Engineering Journal, 165: 693700 . 
[34] Qing W., Chen J., Shi X., Wu J., Hu J., Zhang W. 2016. Conversion enhancement for acetalization using a catalytically active membrane in a pervaporation membrane reactor, Chemical Engineering Journal, 313: 1396-1405.

[35] Peters T.A., Tuin J.V.D., Houssin C., Vorstman M.A.G., Benes N.E., Vroon Z.A.E.P., Holmen A., Keurentjes J.T.F. 2005. Preparation of zeolite-coated pervaporation membranes for the integration of reaction and separation, Catalysis Today, 104 (2-4): 288-295.

[36] Castanheiro J.E., Ramos A.M., Fonseca I.M., Vital J. 2006. Esterification of acetic acid by isoamylic alcohol over catalytic membranes of poly(vinyl alcohol) containing sulfonic acid groups, Applied Catalysis A: General, 311 (1-2): 17-23. 